By the use of the globe we can best study the conditions of observation at the poles of the earth, the equator, and some place in middle latitude. The wooden horizon of the globe is parallel to the horizon of a place

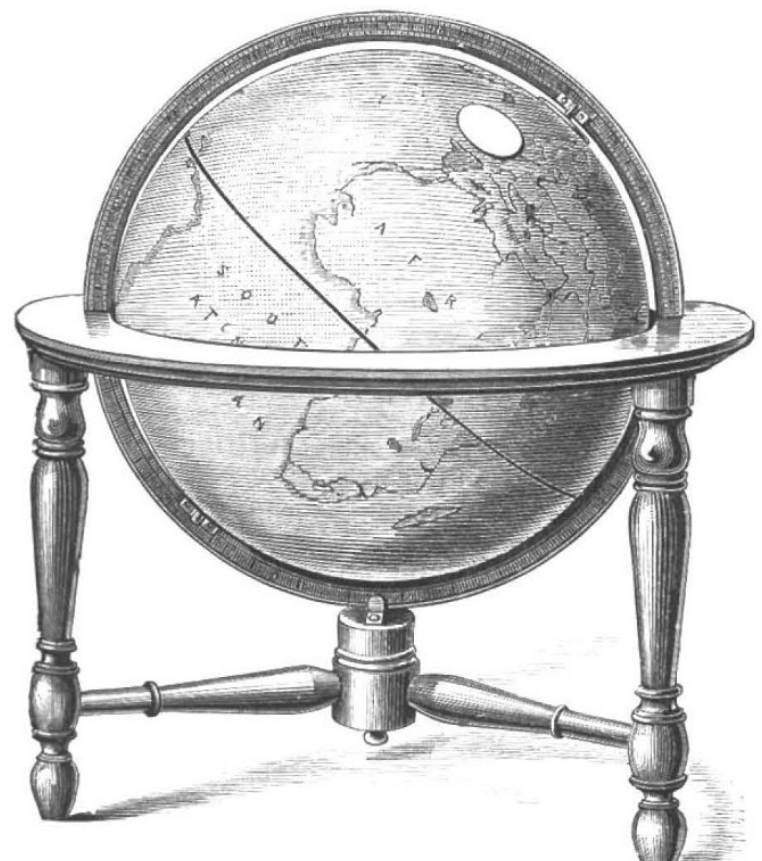

'FIC. 5.-Diagram to show how the inclingtion of the horizon of London will change with the rotation of the Earth.

at the top of the globe, which horizon we can represent by a wafer. In this way we can get a very concrete idea of the different relations of the observer's horizon to the apparent paths of the stars in different latitudes.

J. NORMAN LOCKYER.

(To be continued.)

\section{ADDITIONAL RESULTS OF THE UNITED STATES SCIENTIFIC EXPEDITION TO WEST AFRICA.}

WRITING a year ago from Ascension Island, I gave to NATURE a partial account of the work of the Expedition from October 1889 to March 1890 . Subsequently the U.S.S. Pensacola, Captain A. R. Yates, U.S. Navy, commanding, arrived at Barbados on April 28, at Bermuda on May I8, and terminated her cruise with the Expedition on reaching New York on the 23 rd of the same month.

My previous communication to NATURE (vol. xili p. 8), relates the great obligation of the Expedition to His Excellency Governor Sir H. B. Loch, and to Dr. David Gill, H.M. Astronomer at Cape Town, to His Excellency Governor Antrobus, at Saint Helena, and to Captain Napier, R.N., then in charge of Ascension, acting in accordance with the very liberal instructions of the Admiralty. Although our arrival at Barbados was entirely unexpected, all necessary facilities were at once provided by direction of His Excellency Governor Sir Walter Sendall.

The gravity and magnetic work at Bridgetown occupied nearly a fortnight. Mr. E. D. Preston, in special charge of this department of the Expedition, occupied in all fourteen magnetic stations, of which five were on the West Coast of Africa, and eight on islands of

NO. I I 20 , VOL. 43 ] the North and South Atlantic. The area of the gravity stations extends from Cape Town to Washington, covering a range of $73^{\circ}$ in latitude, and $96^{\circ}$ in longitude. The elevations of these stations range from 7 feet to 2250 feet above sea-level. These observations are now in progress of reduction by Mr. Preston, under the direction of Prof. Mendenhall, Superintendent of the U.S. Coast and Geodetic Survey; and the definitive results will, it is hoped, be available at the conclusion of the present year. "Whether," says Mr. Preston, "they show the Atlantic islands to be heavy or light as compared with the continental masses, they will at least add considerable new material for the determination of the earth's figure."

By direction of the Hon. Secretary of War, and General Greely, Chief Signal Officer of the Army, Prof. Cleveland Abbe was detailed as meteorologist of the Expedition. $\mathrm{His}$ observations and researches, assiduously conducted during the entire cruise of the Pensacola, are so significant that no brief statement can do them full justice. From the forthcoming Report of the Expedition I excerpt the following sections of Prof. Abbe's preliminary report :-

(I) I should mention at the outset that the work with small balloons was carried on sufficiently to demonstrate the practicability of this method of getting the actual velocity of the wind ; but, by the advice of the maker of the balloons, 1 had omitted taking up with me the varnish ordinarily used, as being probably unnecessary and possibiy dangerous to manipulate on ship-board. The result was that I found it would become necessary to use more balloons than originally contemplated. Still I deem it a decided gain to have been able to make enough observations to show that the method of determining the velocity of the wind by small balloons is accurate and practicable, both on land and sea, and but little, if at all, more expensive than the use of self-recording anemometers.

(2) The mirror nephoscope used by me rested on the Ritchie liquid compass (U.S. Navy standard), which was established on the after-bridge, and which compass I was free to use at all times. Although free in its gimbals, yet the compass is by no means exactly horizontal ; so that more numerous observations must be made at sea than on land, if the same resulting accuracy is desired. I was abie to maintain daily observations, and I can but consider that the opportunity thus offered me has been entirely unique in the history of meteorology; and unless I am greatly mistaken in my knowledge of the literature of the subject, it will be found that the results attained will form a valuable basis for further study. My observations have in fact led to some change in my own views as to the general circulation of the atmosphere, and every form of fluid motion has been found by me to be visibly illustrated in the cloud-structure.

(3) I have attempted a simple and rational classification of clouds, based, not on shapes and appearances, but primarily on their modes of formation.

(4) A method of using the nephoscope has been elaborated for the determination of actual heights and velocities of clouds (or balloons) by combining observations made when the observer is moving successively in two different directions, or with two different velocities. The instrument can be used in a waggon, or car, or boat. I call this " the aberration method" as distinguished from ordinary parallax methods.

(5) My work shows that the observed movements of the clouds and the wind have such a relation to the presence of a storm centre, an island, or to any other disturbance, that one should be able to locate the position of such a disturbance by observations made at one locality.

(6) At Fayal, on the summit of Pico, I first observed the formation of a cloud, with which I afterwards became 
familiar in other similar Iocalities, and which must be well known in mountainous countries. Although not often clearly described, this is a slender white stream, which is sometimes likened to a table-cloth or to a soft hood. It has nothing of the boiling vertical motion characteristic of the cumulus; nothing of the curling and rolling motions characteristic of the scud-cloud. It is a smooth stream, of soft appearance, of very gentle curvature, and illustrates an elementary form of fluid motion. It is the simplest cloud that can be formed by the slow steady rise and fall of undulating streams of air. As seen from Fayal, this cloud marked the lowest limit at which the densest cirrus could form in an atmosphere having the temperature and moisture then prevailing. When a mountain obstructs the lower wind, it forms a scud-cumulus, or cumulus whose ascending currents are due to obstructed wind rather than to internal heat. These cumuli themselves obstruct the wind prevailing at their own higher levels. The latter is therefore pushed up, but it rises slowly and smoothly, being a case of "steady motion" without forming discontinuous eddies; and thus generates the smooth white hood, or arched crescent cloud.

The hood will form on the peak itself if the air below the summit is calm, so that scud-cumuli do not form by reason of horizontal winds, or if the lower air be cold or dry and dense, so that the cumuli will not form by reason of heat. In such cases the summit of the peak can itself be considered as a small obstacle to the gentle current at its level. When large cumuli form in open regions, their summits then become like the mountain, comparatively small obstacles to the upper current; and, under these circumstances, beautiful hoods form in the warn moist air ascending on the sunny sides of the cumuli. For the formation of these, it is simply necessary that the upward deflection of the disturbed horizontal motion of the upper current shall be so gentle as not to introduce sudden curves and eddies. Even without the formation of a visible cumulus there may be a large invisible mass of rising air, not yet cooled to saturation; and in such a case the crescent hood may even be seen to form in mid-air, and the cumulus may subsequently become visible. At Green Mountain, on the Island of Ascension, the heavy south-east trade strikes an abrupt surface, and is thrown up to a great height, whence it descends; and, like a standing wave in the river, flows off many miles to leeward. Several times I was able to observe the crescent cloud forming in mid-air in a clear blue sky for a short space only, and evidently at the very summit of the first of these standing waves. On Table Mountain, at Cape Town, the so-called "table-cloth" was, at least during our visit, a mass of rolling scud-cumuli; but above these there were occasionally to be seen small beautiful crescent hoods.

(7) At Freetown, Sierra Leone, the study of two arched squalls showed, as I expected, that they and the African tornado and the afternoon thunderstorms of the eastern coast of the United States are the same in nature and laws, differing only in degree.

(8) At Eimina the study of the Harmattan wind, through which we had been passing for several days, was combined with notes made by a good observer on shore, showing unmistakably that this is a mass of dry, and therefore dense, air flowing from the interior of Northern Africa at this season. It brings with it the fine white ashes due to innumerable local bush-fires in the interior commonly called "dust from the desert"; and the whole phenomenon is analogous to the flow of dry, cold air from Canada, south-eastward over the United States, making our so-called "north-westers." The Bora of Russia and the Pampero of South America have a similar physical origin.

(9) At Cape Ledo I found the finest imaginable opporsunity to study the formation of the overflow from the summit of the cumulus clouds, and its gradual transformation into slowly-dissolving stratus. It was a daily phenomenon at Cape Ledo to observe the large cumuli ascend bodily, lose their flat bottoms, become pear- or balloon-shaped, and then spread out into fields of most beautiful spots, vortices, striæ, curds, and other forms. The "mackerel sky" did not occur at this time. The motion of the lower cumuli was with the lower southwest winds; but the overflow into the stratus and cirrus moved from the east in the afternoons out westward over the sea. But if these clouds endured over night, as they usually did, then in the morning they were found to have descended, and to be moving from the west toward the land; while below them the cool, easterly land breeze existed for a few hours with a slight scud or cloud-rip on its upper surface.

(Io) At Cape Town we experienced an unusually heavy south-easter. There had also heen a remarkably destructive north-westerly storm in the previous July. I made detailed maps illustrating the south-easter, and obtained from $\mathrm{Mr}$. A. G. Howard his own maps illustrating the storm of July, all based on the data of the Meteorological Commission for South Africa. These maps were made the basis of an address to the South African Philosophical Society on the practicability of storm warnings, and I think it may safely be anticipated that within a few years there will be such a system in active operation at all the ports on the South African coast. The remarkable development of rare and beautiful flowers over the whole of Table Mountain is, of course, possible only by virtue of the damp atmospluere and the steady drip of fog-particles from leaves and rocks, quite as much as by virtue of the rain. fall, as ordinarily measured.

(I I) At Saint Helena my attention was attracted first of all to the matter of rainfall. A previous study of the subject had convinced me that the local temperature of the air over the land could have little or nothing to do with the rainfall in a small isolated tropical island; that the extraction of the moisture as rain from the air must be done in cumuli that are formed by the impinging of the trade-wind upon the island as an obstacle to its progress, and not in cumuli carried up by heat of an overheated land-surface; and that therefore the rainfali of Saint Helena was a direct indication of the average wind striking against the island, since the moisture is so uniform. I consider the Saint Helena rainfall as the best index to the average movement of the air, and as depending therefore, like the movement of the air, on the meteoro. logical conditions over a large surface of the ocean. Similar considerations apply to other islands, as Ascension and Barbados, at both of which I have therefore made the rainfall a matter of special solicitude. At Saint Helena my attention was attracted by "the rollers" as being an unsolved problem in ocean meteorology, and I made arrangements for future observations to be kept by Mr. George Bruce, of the Customs Department, rather more fully than hitherto.

(I5) At the Island of Ascension I was so fortunate as to be allowed to occupy the signal station at the summit of Cross Hill, a steep conical hill of volcanic cinder rising to 870 feet above the sea-level, and immediately overlooking Garrison and the landing-place on the leeward side of the island, as well as the lowlands of the interior of the island to windward, with Green Mountain bearing east-south-east about three miles distant. Here I observed, not only the motions and phenomena of clouds above me, but also observed their shadows on the ground and sea beneath me, so that I was able to determine the heights and linear velocities by the simplest mathematical methods. Certainly there are few, if any, spots in the world where the phenomena of the trade-winds with their annual and their irregular changes can be more successfully observed. I have certainly never before occupied a position so favourable for all manner of studies of the

NO. I 120 , VOL. 43] 
clouds, winds, twilight phenomena, and the "rollers"; nor could any place be found where these particular phenomena are more highly developed.

(I6) With regard to the "rollers," I would say that previous studies at Saint Helena had led me to think that undoubtedly the heavy surf constituting their prominent characteristic as described by all previous observers must be due to distant winds, not necessarily storms; and that, as an earthquake wave can traverse the whole of an ocean in a day, so the heavy swell attending a hurricane or a "norther," could easily pass to Ascension and Saint Helena from the most distant parts of the North Atlantic Ocean.

Within a week the "single-roller flag," and finally the "double-roller flag" was displayed at the Garrison landing, and I found myself looking down upon the phenomenon that had so long been a mystery. The first glance showed that the character of the phenomenon had been wholly mistaken; and on subsequent inquiry I found that probably no observer of intelligence had ever undertaken the slight hardship of a solitary residence on Cross Hill for the purpose of studying the rollers.

Otherwise it would be inconceivable that some one should not ere this have recognized a feature that certainly could never be seen from the deck of a vessel or from a lower station-namely, that the rollers are essentially the deflection around to the leeward side of what would be merely a heavy swell on the windward side of the island; and that the double rollers are simply the interference of the two sets of rollers coming around the island by the right hand and by the left. A swell such as would be caused in the open sea by a trade.wind of force 4, blowing for two days over a limited part of the ocean, will, on reaching the windward side of Ascension, or Saint Helena, produce a phenomenon on the leeward side precisely such as anyone can reproduce by studying the interference of waves in shoaling spots in a small tub of water. The angle at which the rollers interfere to produce double rollers at Garrison landing is about $135^{\circ}$; and as you proceed further from the island to leeward, the angle diminishes. When we sailed away from the island I was able to determine the angle as being about $40^{\circ}$ at about fifteen miles distance. It will be at once a matter of surprise that rollers are peculiar in their severity at Ascension and Saint Helena; for other islands might be expected to show similar phenomena. But the fact is that the severity of the rollers depends first on the shape of the island; second, on its size; third, on the location and character of the shoals which surround it, all taken in connection with the length and height of the original swell; so that we should not expect many islands to possess the necessary combination of peculiarities. In fact, I have thus far learned of only one other island-namely, Saint Paul de Noronha, where the roller phenomena are conspicuous. At the Island of Barbados I particularly observed an appreciable swell curl around to the leeward side of the island from both its northern and southern extremity, and was told that occasionally these (which might be so-called single rollers) would be troublesome; but the island is so shaped that before these rollers interfere and conspire together, they have dwindled into an unimportant swell.

(I7) Our second approach to and passage through the doldrums, in April 1890, served to give me the clue to a satisfactory solution of the question. as to how it is that the north-east trades interact at the equator-namely, whether they pile up over the doldrums and flow back as massive upper currents, according to the ancient theory; or whether they interpenetrate each other, according to Maury's theory; or whether they revolve around each other in horizontal curves, slipping past each other to the north and south ; or whether they meet and conspire together in a powerful upper easterly wind, as Abercromby maintains. This question is now readily settled by reNO. I I 20 , vOL. 43 ] cognizing that the important general features of the circulation in the lower atmosphere are as follow :--As the trades approach the doldrums from either side, there is a continual diurnal uprising and return flow taking place, so that the returning upper anti-trades are perpetually being supplied by new air, and derive scarcely any of their material from the central region of the doldrum itself. Each successive ascending mass diminishes the inertia of the matter in the lower trade wind by necessitating the descent of a little air from the antitrade, so that the inertia of the lower trade considered as a whole is all used up by the opposition of these descending waves, some time before it can reach the doldrums. This causes the broad irregular calm space near the equator to have no horizontal motion, and only a diurnal vertical interchange. "The motion of this doldrum region horizontally in either direction depends upon the balance of pressure on the great areas of moving air around it ; and it can, I believe, be deduced from anemometer records from a few such island stations as Ascension and Saint Paul de Noronha. A vertical section of the trades would show them to be wedge-shaped, being shallower at the high latitudes, while the overlying anti-trades are deeper at high latitudes. In the doldrums, as high up as clouds are formed, the prevailing characteristic of the circulation is a vertical one repeated diurnally for months and years without any systematic interchange of air to the north or south.

(20) At Barbados I was able to secure a large amount of manuscript meteorological data, and was delighted to find that the magnificent system of rainfall stations developed by Sir Rawson W. Rawson, Governor at Barbados 1866-75, is still maintained by the Government; and although the number of stations had failen from 250 to 80 , yet the system remains one of the best in the world.

Cleveland ABbe.

The unfortunate appearance of "the grip" on board the Pensacola, when two days out from Barbados, caused our prompt quarantine on reaching Bermuda. Meteorological work at the latter place was, therefore, necessarily much abridged. Mr. Preston was, however, permitted to land with his instruments at Quarantine, Nonsuch Island; and by remaining after the departure of the Pensacola, he was enabled, through the courtesy of $\mathrm{H}$ is Excellency Governor Lieut.-General Newdigate-Newdegate, to carry on the magnetic and gravity work as elsewhere, thus preserving the chain of Expedition stations un broken.

Amherst College Observatory, Massachusetts, March 24.

\section{VEGETATION OF LORD HOWE ISLAND.}

THERE is nothing absolutely new to announce concerning the flora of this remote islet; but what has been published is in the form of Government reports, which have a comparatively restricted circulation, and many persons who would be interested in their contents are unaware of their existence. And even when one knows of the existence of such reports, it is often difficult to procure them. Through the intermediary of Sir Saul Samuel, Agent-General for New South Wales, the library of the Royal Gardens, Kew, has just received a copy of a report on the state and prospects of Lord Howe Island, with a number of photographic illustrations of the scenery and vegetation of the island; and it is on account of some of these illustrations that I have thought it worth while making known to the readers of NATUkE the existence of such a report, though it was published as long ago as 1882 . Unlike the majority of such documents, this report is too meagre; "Thompson's 